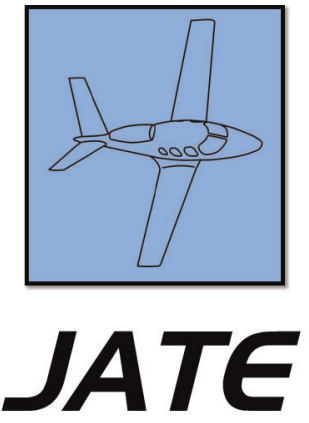

Journal of Aviation Technology and Engineering 10:2 (2021) 51-57

\title{
Benchmarking Global Carrier Status in the Airline Industry
}

\author{
Darren Ellis ${ }^{1}$ and Steven Leib ${ }^{2}$ \\ ${ }^{1}$ Cranfield University \\ ${ }^{2}$ University of South Australia
}

\begin{abstract}
Over the past decade or so and through the onset of the COVID-19 pandemic, a number of airlines have risen to global prominence in Asia (especially China), the Middle East, Latin America, Africa, and elsewhere. As each develops, many industry observers are questioning the extent to which these airlines will rival current industry heavyweights around the world. This paper aims to provide a basis for assessing what constitutes a major global carrier in the airline industry, including the likelihood of being so in the foreseeable future. Three key metrics are employed to gauge the global reach of an airline and its corresponding major global carrier status and rank: wide-bodied fleet size, the number of international destinations flown to, and continents served (squared for adequate amplification). Data are sourced from the Centre for Aviation (CAPA) airline database. The paper concludes that major global carrier status for an airline is best viewed in relation to key competitors including the ranking location of those directly above and below any given airline. This ranking approach is therefore about insights generated and is not premised on precise locations on a leader board.
\end{abstract}

Keywords: major global carrier, major airline, airline industry, global reach, benchmarking

\section{Introduction}

As the global airline industry progressively emerges from the COVID-19 pandemic sweeping the world, it seems as pertinent as ever to closely consider what constitutes a global carrier or airline. Which airlines will survive the current crisis, and which will go on to expand and thrive in future, is to some extent dependent on the size and scope of each before the crisis hit. This is especially relevant to emerging air markets where much of the global industry's growth and development had been taking place in the lead-up to the COVID-19 pandemic. This paper considers the state of the industry mostly in January 2019, and, consequently, for the most part excludes the current global pandemic.

The opportunities and challenges linked with the likely future scale and scope of global civil aviation development present myriad possibilities, and therefore a corresponding need to better understand the wider aviation industry implications of this overall trajectory. One important aspect of this is to assess the extent to which major airlines in emerging markets are competing with established industry competitors in terms of size, scope, product offering, and global reach (Ellis, 2018). In these respects, this paper aims to establish a basis for investigating the extent to which major emerging air market airlines would be considered global carriers now and into the foreseeable future. This aim is predicated on an international focus, including international network realities and future developments. Domestic air markets tend to 
follow orthodox economic concepts and theories, while international air markets are subject to political forces whereby decisions are often predicated on wider trade and connectivity considerations. Amongst other things, this then means that national flag carriers rarely exit the marketplace (Doganis, 2019).

\section{Theory}

\section{Understanding Major Global Carrier/Airline}

Any assessment of major global carrier status in the airline industry requires a discussion of what constitutes such an airline to begin with. This paper uses carrier and airline interchangeably throughout. Iatrou and Oretti (2007) employ a range of labels in their book Airline Choices for the Future: From Alliances to Mergers including "global player" (p. 3), "major and minor airlines" in a European single air market context, and "mega-carriers" after consolidation in the U.S. domestic air market (p. 11). They also refer to "medium sized airlines" and "the big players" (p. 199). Similarly, Hanlon (2007) in his book Global Airlines: Competition in a Transnational Industry refers to "large airlines" and "large carriers" throughout (p. 9). Meanwhile, Wensveen (2007) in his book Air Transportation: A Management Perspective notes "major carriers" in a U.S. context (p. 151). It is worth noting that efforts to quantify and articulate an airline's size and international scope closely mirror similar attempts to classify, cluster, and rank global airports (Mayer, 2016), and to rank airlines based on fuel efficiency (Chandra et al., 2014).

Meanwhile, Wang et al. (2014) list "eleven major network carriers" for their benchmarking investigation into the big three Chinese airlines (p. 5). The eleven airlines were chosen as they "account for a significant share of the global market," and are "some of the most successful and well-established airlines in the world" (p. 5). It is also argued that these airlines reflect the current global industry with respect to "geographic location, network coverage, and global airline alliances" (p. 5). However, with British Airways missing in the above article, along with Emirates Airline, Qatar Airways, and Turkish Airlines, it becomes less clear what metrics work best in determining a carrier's global status if such airlines, and potentially others, are omitted. What does seem clear though is that "the prime objective of any airline wishing to become a global player is to expand the geographic scope of its network" (Iatrou \& Oretti, 2007, p. 3).

What then is a major global carrier? The literature does not explicitly define a major global carrier, and classification of air carrier size is a surprisingly difficult distinction to make. In the United States, domestic airlines have been historically categorized into three groups based on annual operating revenue. Group I "regional carriers" are those that have operating revenues of less than US\$100M, Group II are "national carriers" with operating revenues between US\$100M and US\$1B, and Group III are "major carriers" which exceed US\$1B in annual revenues (Wensveen, 2007, p. 153). Meanwhile, Hanlon (2007) ranks the top 100 airlines in the world in 2004 based on annual passenger kilometers, although annual passenger numbers and total employees are given alongside in the ranking table too. He also highlights "fleet size" and "sales revenues" as relevant metrics to be considered (p. 11). While operating revenue provides some indication as to the size of a carrier, it does not reveal the scale of an airline's international network nor its global reach. Other aspects of an air carrier may also be relevant to understanding its scale and scope. In 2017, American Airlines had the largest revenue passenger miles, a measure of utilized capacity, while Southwest Airlines carried the most passengers (Bureau of Transportation Statistics [BTS], 2017). The multifaceted approach to measuring airline size makes it challenging to effectively categorize air carriers, and even more difficult to establish a consistent and balanced standard by which to compare airlines.

Considerable differences in global scale, airline networks, geography, fleet size, and revenues all help to highlight the difficulty of establishing a precise standard for a major carrier. For example, by capacity, Southwest Airlines is larger than Singapore Airlines (BTS, 2017; Singapore Airlines, 2017). However, Singapore Airlines operates globally, with multiple classes of service, and is the largest carrier of its country of origin. Singapore Airlines is also part of the global airline alliance Star Alliance that as a whole eclipses Southwest Airlines from an operational standpoint. Airlines are also often part of wider groups which can include low-cost carriers (LCCs) and regional airlines. This kind of variation in air carrier operating profiles suggests that not only is it difficult to establish the size of a carrier, but also to even compare the size of carriers in a meaningful way.

\section{Defining Major Global Carrier}

Based on the scholarly literature, this paper aims to approach a comparative definition linked to the notion of major global carrier score $(G C S)$ premised on the following operational profile aspects of an airline:

- its wide-body fleet $(W)$;

- its international network $\left(N_{i}\right)$; and

- the number of continents it directly serves $(C)$, with a minimum of two outside its principal base of operations.

These three metrics are readily available across all airlines in the world, and are more stable than a range of financial metrics which are often open to wide interpretation based on accounting techniques, availability of data, 
and questions surrounding data accuracy. Added to this, many airlines do not provide a breakdown of their domestic and international passenger numbers, making the latter measure impractical to utilize as well. Data availability and accuracy are particularly relevant challenges in emerging air markets (Itani et al., 2014). Even when an airline does provide these data, there is some duplication as international passengers often connect to a domestic flight as part of their overall journey. Likewise, both revenues and profitability seem to have intuitive value in determining major global carrier status, but government ownership and a lack of reliable financial data in many cases make these very difficult to consistently gauge across a large cohort of global carriers home based across the world. Added to this, profitability is not, and arguably has never been, a prerequisite for being a major airline (Rhoades, 2016).

The inclusion of wide-body fleet size then excludes all narrow-body fleet operators such as regional LCCs like Ryanair, easyJet, and Wizz Air which all concentrate on short-haul international destinations predominantly within one region. This would also include predominately domestic LCCs like the aforementioned Southwest Airlines. Major global carriers also focus on "global reach" (Hanlon, 2007, p. 13; Iatrou \& Oretti, 2007, p. 3), and this requires international networks at least in part built around long-haul flights that can only be operated by wide-body aircraft. Technology has dramatically "extended the range of aircraft reducing the need for multi-leg flights" and has helped to provide some countries such as the United Arab Emirates and Qatar with geographic "comparative advantages" (Lumbroso, 2019, pp. 24, 27). The Airbus A321neo and Boeing 737 MAX are also extending the range of single-aisle narrow-body aircraft; however, their exclusion here does not significantly skew results at present (McCarthy, 2018). The essential argument here is that big global operators use big jets, even if part of a mixed fleet that includes narrow-body aircraft as well. Global geographic reach is certainly achieved via global alliance membership (Hanlon, 2007), but this alone does not provide a sense of the size and scope of an actual airline as many regional and small carriers often have a plethora of code share, strategic, and alliance partners. Virtual is not the same as actual (i.e., an airline using its own metal/aircraft). This paper only considers each airline's own metal so as to ascertain the size of a carrier based on its actual assets, chiefly the number of wide-bodied aircraft it owns or leases and operates under its own brand.

\section{Method}

\section{Benchmarking and Ranking Major Global Airlines}

This paper seeks to explore a consistent and accessible method to benchmark and rank major global airlines. Benchmarking global airlines and ranking their performance are common practice in the academic literature
(Chandra et al., 2014; Fry et al., 2005; Wang et al., 2014). Evidently, there are numerous ways to compare and contrast international airlines; however, obtaining consistent data across all airlines in a global sample is challenging. Differing ownership models, accountancy standards, exchange rate fluctuations, and the public availability of data, to name some prominent examples, make the exercise of standardized global airline comparisons very challenging. Devising an insightful and accessible set of metrics which address these challenges is not easy. Benchmarking is employed in this paper to generate key insights, not to establish rigid parameters or narrow conclusions. Therefore, this paper is intended to be exploratory and realistic, not prescriptive and impractical to widely apply in practice. Air transport research focused on developing insights is often based on the realities and challenges of "obtaining access to traditional airline data sources" (Lohman \& Vianna, 2016, p. 203).

One quick and effective way to visualize what a major global airline looks like is to benchmark big carriers in the USA, Europe, Asia, the Middle East, and elsewhere in terms of wide-body fleet size, number of international destinations operated, and continents served (out of six inhabited). A number of aviation databases contain information on each of these metrics, and this paper is based on the database provided by the Centre for Aviation (CAPA, 2019). All data were accessed in January 2019. This date allowed for a snapshot in time when the global airline industry was by all accounts expanding and thriving, albeit with some cooling off evident in the Middle East (IATA, 2019). Data for all three selected metrics can be sourced from individual airline websites and annual reports as well; however, dedicated aviation databases provide a less time-consuming centralized approach. The selected metrics are founded on the contention that simplicity is often the antidote for complexity; while available is the pragmatic antithesis of unattainable.

The comparative major global carrier score $(C G S)$ was calculated as $G C S=W+N_{i}+C^{2}$. By multiplying the number of continents served by itself, a modest and meaningful differentiation can be achieved whereby three continents become a score of nine points, while six continents are converted to 36 . This way, airlines which operate a more geographically dispersed intercontinental network are boosted in their final score, but not to the extent that the results are unreasonably skewed. The cube for each was also considered; however, the resulting differences for two to six continents (respectively 8, 27, 64, 125, and 216) were decided to be too great. Alternatively, continents served could be employed as a filter rather than a key metric. The intent in this paper is to try and account for global reach, and the number of international destinations operated to does not fully capture this, as some airlines concentrate their international operations within a region and/or continent. The three metrics of wide-bodied fleet size, 
number of international destinations, and continents served are by no means perfect, but they do generate a global rank order of value and insight consistent across all global carriers. Although it is true that some global airlines operate a significant number of narrow-body aircraft in mixed fleets, like Turkish Airlines, these are often employed on regional and domestic routes, and therefore do not play central roles in achieving substantial intercontinental global reach (Dursun et al., 2014).

\section{Results and Discussion}

When the three chosen metrics are used in aggregate, many of the individual anomalies which can occur are greatly reduced, including where wide-bodied aircraft are extensively used on domestic routes (e.g., the USA), where international destinations are concentrated in a single region (e.g., easyJet, Ryanair, and Wizz Air in Europe), and where only limited services are operated to a specific continent (e.g., South African Airways to Perth only in Oceania). Figure 1 provides a table of global airlines ranked based on these identified metrics. For instance, both Qantas Airways and South African Airways (SAA) served all six inhabited continents in 2019, but with only one daily service each to South America, and the same to Africa (Qantas) and Oceania (SAA), respectively. When widebodied fleet size and international destinations served are added, the boost that each airline receives for continents served is more accurately reflected in their lower global status and ranking. In a similar fashion, it is also worth

\begin{tabular}{|c|c|c|c|c|c|c|}
\hline & Airline & $\begin{array}{l}\text { Wide-Body } \\
\text { Fleet }(W)\end{array}$ & $\begin{array}{l}\text { International } \\
\text { Destinations }\left(N_{i}\right)\end{array}$ & $\begin{array}{l}\text { Continents } \\
\text { Served }(C)\end{array}$ & $C^{2}$ & \begin{tabular}{|l} 
Global \\
carrier \\
Score \\
$(G C S)$
\end{tabular} \\
\hline 1 & Emirates Airline & 271 & 140 & 6 & 36 & 447 \\
\hline 2 & Turkish Airlines & 105 & 220 & 5 & 25 & 350 \\
\hline 3 & Qatar Airways & 157 & 152 & 6 & 36 & 345 \\
\hline 4 & British Airways & 130 & 177 & 6 & 36 & 343 \\
\hline 5 & United Airlines & 183 & 113 & 5 & 25 & 321 \\
\hline 6 & Lufthansa & 101 & 176 & 5 & 25 & 302 \\
\hline 7 & American Airlines & 154 & 114 & 5 & 25 & 293 \\
\hline 8 & Cathay Pacific Group & 165 & 100 & 5 & 25 & 290 \\
\hline 9 & Air France & 104 & 152 & 5 & 25 & 281 \\
\hline 10 & Delta Air Lines & 150 & 93 & 6 & 36 & 279 \\
\hline 11 & Air Canada & 98 & 127 & 6 & 36 & 261 \\
\hline 12 & KLM & 66 & 153 & 5 & 25 & 244 \\
\hline 13 & Korean Air & 125 & 96 & 4 & 16 & 237 \\
\hline 14 & LATAM & 72 & 127 & 6 & 36 & 235 \\
\hline 15 & Air China & 115 & 76 & 6 & 36 & 227 \\
\hline 16 & ANA & 149 & 44 & 4 & 16 & 209 \\
\hline 17 & China Southern & 97 & 75 & 6 & 36 & 208 \\
\hline 18 & Singapore Airlines & 121 & 61 & 6 & 25 & 207 \\
\hline 19 & Ethiopian & 55 & 103 & 5 & 25 & 183 \\
\hline \multirow[t]{2}{*}{20} & Etihad Airways & 76 & 76 & 5 & 25 & 177 \\
\hline & Saudia & 90 & 63 & 4 & 16 & 169 \\
\hline \multirow[t]{2}{*}{21} & China Eastern & 74 & 79 & 4 & 16 & 169 \\
\hline & Japan Airlines & 115 & 38 & 4 & 16 & 169 \\
\hline 22 & Norwegian Air & 35 & 103 & 5 & 25 & 163 \\
\hline 23 & Thai Airways & 79 & 58 & 3 & 9 & 146 \\
\hline 24 & Iberia Airlines & 41 & 75 & 5 & 25 & 141 \\
\hline 25 & Asiana & 57 & 66 & 4 & 16 & 139 \\
\hline 26 & Hainan Airlines & 67 & 53 & 4 & 16 & 136 \\
\hline 27 & Qantas Group & 68 & 25 & 6 & 36 & 129 \\
\hline 28 & $\begin{array}{l}\text { South African } \\
\text { Airways }\end{array}$ & 27 & 43 & 6 & 36 & 106 \\
\hline 29 & Air India & 45 & 40 & 4 & 16 & 101 \\
\hline 30 & Air New Zealand & 28 & 28 & 5 & 25 & 81 \\
\hline
\end{tabular}

Figure 1. World airline rankings, January 2019. (Source: Complied with data from CAPA database January 2019). 
noting that Air New Zealand is ranked below Qantas and SAA, with all three airlines referred to as end-of-line carriers due to their geographical home base locations in the southern hemisphere away from the major global traffic flows across the northern hemisphere (Ellis, 2018).

China is a good case in point in terms of the extent to which airlines in emerging air markets are considered competitive with both the hard and soft products and services of more established international airlines. Many experts now argue that China's aviation industry's reputation lags more recent realities (Calder, 2018). They maintain that China's main airlines have steadily built reputations for "safe and affordable air travel," while its airport infrastructure puts many "European or US terminals to shame" (Calder, 2018, paras. 7 and 8). China is no doubt developing a significant domestic air market, but will it be widely viewed as being on a par with the USA and EU in the foreseeable future? China's airline industry is somewhat challenging for experts to forecast, but its general ascendency is widely agreed by most experts to be headed in a direction of ever growing significance, including in comparison to major rivals elsewhere (Zhang et al., 2014). The metrics used in this paper help to situate the major Chinese carriers into a tangible and relatable global context and rank order.

In this context, and as shown in Figure 1, Emirates Airline is in a clear first position with its all-wide-body fleet of 271 aircraft (including 109 Airbus A380s), 140 non-stop international passenger destinations, and six continents served as at late January 2019 (CAPA, 2019). The three major Gulf carriers-Emirates Airline, Etihad Airways, and Qatar Airways-have certainly had a big impact on global aviation over the past decade or so (Ellis, 2019). Even so, Etihad's 20th position in the rankings here does help to reveal its more recent woes (Ellis, 2019), and to contrast its status with first-placed Emirates and third-placed Qatar. Meanwhile, second-placed Turkish Airlines served 220 international destinations with 105 wide-body aircraft across five continents (CAPA, 2019). Turkish Airlines' narrow-body fleet, and proximity to many short-haul international destinations in Europe, the Middle East, and Asia, mostly explains the difference between the two top placed carriers here (Dursun et al., 2014). Air China is ranked just inside the top 15 airlines in the world at 15th, while China Southern is inside the top 20 at 17th position, and China Eastern shares 21st place with Saudia and Japan Airlines (CAPA, 2019).

Evidently, when the number of international destinations for an airline exceeds the number of wide-bodied aircraft in its fleet, a shift toward more short-haul destinations occurs. In addition, this trend also reflects a mixed fleet which often includes narrow-body aircraft on many of these international routes. Once again Emirates and Turkish Airlines demonstrate this situation well, as Turkish Airlines at January 2019 had almost 200 narrow-body jets in its fleet and Emirates had none (CAPA, 2019). When the opposite occurs, and an airline has many more wide-bodied aircraft than international destinations, there are two possible implications: firstly, that airlines like Emirates have mostly long-haul networks; and secondly, as is the case of Japan Airlines and All Nippon Airways, a trend toward using wide-body aircraft extensively on domestic networks, and/ or on short-haul international routes.

Although the COVID-19 pandemic has placed considerable downward pressure on the rankings here, the use of the method detailed in this paper provides the basis for key preand post-pandemic insights which will help to determine recovery trajectories. Financial data, passenger traffic, and other key airline metrics are likely to fluctuate considerably as the global airline industry emerges into the postpandemic world. As more aircraft return to fleets (or are retired), and more destinations come online together with continents served, an insightful and meaningful sense of an airline's recovery trajectory and prospects can be gauged by employing these three metrics as salient reference points; combined, even more so.

\section{Conclusion}

Quantifying what is meant by major global carrier in the airline industry is an important way to better understand where such carriers are located around the world, and to provide a basis for a deeper appreciation for why such airlines have achieved this status. Thus, this paper argues that having a substantial number of wide-bodied big jets and numerous international destinations across multiple continents is vital for achieving major global carrier status. The real value of this method is that it is straightforward to calculate, based on easy-to-find publicly available data which remain consistent and reliable across regions, business models, and ownership profiles. These three metrics, especially when combined, provide a flexible but insightful comparative baseline to then delve deeper into other areas of investigation.

Available, consistent, and accurate data across such a large, dynamic, and complex system as global aviation are challenging to acquire. The long historical data record in well-established and mature air markets like those of the USA and Europe cannot be fully compared with emerging air markets which have only more recently entered an accelerated rate of growth and development. In this context, even if the same financial and other key metrics were available across global airlines, differing stages of evolution would likely mask or distort analysis of the resulting data.

The rise of the three major Gulf carriers-Emirates Airline, Qatar Airways, and Etihad Airways-along with the evolution of other major global carriers like the big three in China (Air China, China Southern, and China Eastern), together with Turkish Airlines, Ethiopian 
Airlines, and LATAM Airlines, to name a brief prominent contemporary list, all demonstrate how an accessible and insightful benchmarking process can help to generate wider industry insights. Before the COVID-19 pandemic, global air travel was on an impressive growth trajectory. Though grounded in large part throughout most of 2020 and into 2021, global aviation has still not extensively expanded into many countries and regions of the world, with much growth yet to come. As airlines move up through the ranks to become major global carriers, and still others face shifting fortunes as these new competitors expand, benchmarking will continue to play an important role in better understanding the industry's future trajectory and prospects.

\section{Limitations}

The metrics selected here to gauge major global carrier status do not consider passenger numbers, load factor, or financial considerations. Although these would all provide greater insight into an airline and its global operations, consistently finding data to cover these across all global airlines is challenging, and in many cases not possible. It is also important to note the limitations to the calculation of global carrier score $(G C S)$ itself-specifically to how it weights each of the three chosen metrics. Other combinations of weightings should be explored as a more refined understanding of what constitutes a global carrier emerges.

Added to this, the data presented in this paper are a snapshot in time, and are not indicative of wider trends or longer-term realities. Data availability did not extend to historical fleet information and was limited to the date of access only. Time series data across all three metrics would provide deeper insights; however, such data are typically more costly to access from database providers.

\section{Future research}

Cost implications to one side, in order to better understand the directional movement of carriers over time it would be valuable to produce a ranking of global carriers at time intervals of three to five years. This approach would lead to clearer insights into which carriers are moving in what direction, including those that have maintained a relatively stable position for some time. For example, Hanlon's (2007) global ranking table utilizes mostly annual passenger kilometer numbers from 2004 and places the three big U.S. carriers at the top of the list, with Turkish Airlines in 48th position and Qatar Airways 70th. The table in Figure 1-admittedly based on different metrics-but 15 years later, locates Turkish Airlines at second place and Qatar Airways in third place, with the U.S. majors occupying fifth, seventh, and tenth places, respectively. Again, directional movement as with global ranking more generally does not reveal why the movement is occurring (or has occurred), but it is often a valuable reference point to build a wider and deeper level of discussion and analysis. Research into the post-pandemic airline industry would benefit greatly from a clearer sense of which airlines have survived, and which of these are able to return to prepandemic levels, and even thrive heading forward.

\section{Acknowledgments}

The authors wish to thank two anonymous reviewers who both provided valuable and actionable feedback and suggestions that strengthened the paper considerably.

\section{Author Bios}

Darren Ellis is a lecturer in air transport management at Cranfield University in the United Kingdom. Darren received his $\mathrm{PhD}$ in airline strategic management from the University of New England (UNE), Australia, in 2017. He also holds a master of aviation management from Griffith University, Australia.

Steve Leib is a lecturer in aviation at the University of South Australia in Australia. Steve received his $\mathrm{PhD}$ in aviation safety from Purdue University in 2014. He also completed a master's degree in aviation/aerospace management from Purdue University.

\section{References}

Bureau of Transportation Statistics. (2017). Airline rankings 2017. Retrieved from https://www.bts.gov/airline-rankings-2017

Calder, S. (2018, February 9). Why Chinese airlines can offer such cheap flights. The Independent. Retrieved from https://www.independent.co. uk/travel/news-and-advice/air-china-airlines-cheap-flights-whyairports-beijing-aviation-a8201931.html

CAPA. (2019). Centre for Aviation. Retrieved from https:// centreforaviation.com/ [subscription required].

Chandra, S., Chitgopeker, C. K., Crawford, B., Dwyer, J., \& Gao, Y. (2014). Establishing a benchmark of fuel efficiency for commercial airline operations. Journal of Aviation Technology and Engineering, 4(1), 32-39. https://doi.org/10.7771/2159-6670.1097

Doganis, R. (2019). Flying off course: Airline economics and marketing (4th ed.). Routledge.

Dursun, M. E., O'Connell, J. F., Lei, Z., \& Warnock-Smith, D. (2014). The transformation of a legacy carrier: A case study of Turkish Airlines. Journal of Air Transport Management, 40, 106-118. https:// doi.org/10.1016/j.jairtraman.2014.06.003

Ellis, D. (2018). The global airline industry and international relations: The globalization paradox. Global Studies Journal, 10(4), 19-38. https://doi.org/10.18848/1835-4432/CGP/v10i04/19-38

Ellis, D. (2019). The strategic context of the three major Gulf carriers. Transportation Research Procedia, 43, 188-198. https://doi.org/10. 1016/j.trpro.2019.12.033

Fry, J., Humphreys, I., \& Francis, G. (2005). Benchmarking in civil aviation: Some empirical evidence. Benchmarking: An International Journal, 12(2), 125-137. http://dx.doi.org/10.1108/14635770510593077

Hanlon, P. (2007). Global airlines: Competition in a transnational industry (3rd ed.). Butterworth-Heinemann.

IATA. (2019, March 7). 2019 starts on a positive note for passenger demand. International Air Transport Association (IATA) Press Release 
No. 13. Retrieved from https://www.iata.org/en/pressroom/pr/2019-0307-02/

Iatrou, K., \& Oretti, M. (2007). Airline choices for the future: From alliances to mergers. Ashgate Publishing.

Itani, N., O'Connell, J. F., \& Mason, K. (2014). A macro-environment approach to civil aviation strategic planning. Transport Policy, 33, 125-135. http://dx.doi.org/10.1016/j.tranpol.2014.02.024

Lohmann, G., \& Vianna, C. (2016). Air route suspension: The role of stakeholder engagement and aviation and non-aviation factors. Journal of Air Transport Management, 53, 199-210. http://dx.doi.org/10.1016/ j.jairtraman.2016.03.007

Lumbroso, A. (2019). Aviation liberalisation: What headwinds do we still face? Journal of Air Transport Management, 74, 22-29. https://doi. org/10.1016/j.jairtraman.2018.09.003

Mayer, R. (2016). Airport classification based on cargo characteristics. Journal of Transport Geography, 54, 53-65. https://doi.org/10.1016/ j.jtrangeo.2016.05.011

McCarthy, N. (2018, August 16). Transatlantic in a 737: The new trend of narrowbody airliners flying long haul. Forbes. Retrieved from https://www.forbes.com/sites/niallmccarthy/2018/08/16/transatlanticin-a-737-the-new-trend-of-narrowbody-airliners-flying-long-haulinfographic/\#

Rhoades, D. L. (2016). Evolution of international aviation: Phoenix rising (3rd ed.). Routledge/Taylor \& Francis Group.

Singapore Airlines. (2017). Annual report FY2016/17. Retrieved from https://www.singaporeair.com/saar5/pdf/Investor-Relations/AnnualReport/annualreport1617.pdf

Wang, K., Fan, X., Fu, X., \& Zhou, Y. (2014). Benchmarking the performance of Chinese airlines: An investigation of productivity, yield and cost competitiveness. Journal of Air Transport Management, 38, 3-14. https://doi.org/10.1016/j.jairtraman.2013.12.012

Wensveen, J. G. (2007). Air transportation: A management perspective (6th ed.). Ashgate Publishing.

Zhang, Q., Yang, H., Wang, Q., \& Zhang, A. (2014). Market power and its determinants in the Chinese airline industry. Transportation Research Part A: Policy and Practice, 64(0), 1-13. http://dx.doi.org/10.1016/ j.tra.2014.03.003 